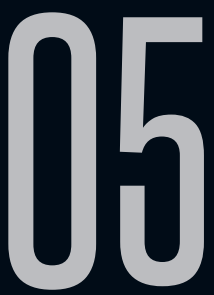

\title{
MAIS MONSTRUOSOS QUE OS MONSTROS: ANSIEDADES TECNOLÓGICAS E O FUTURO SOMBRIO EM ANDROIDES SONHAM COM OVELHAS ELÉTRICAS?
}

Luiz Felipe Voss Espinelly (FURG) Marina Pereira Penteado (FURG)

Recebido em 15 jan 2020. Marina Pereira Penteado é Doutora em Literatura Aprovado em 26 mai 2020. Comparada pela Universidade Federal Fluminense - UFF, já atuou como professora substituta na graduação em cursos da Universidade Federal do Rio Grande-FURG. Autora dos artigos Do contágio ao isolamento: o futuro distópico insistente em The Rag Doll Plagues e Sleep Dealer, publicado na revista Línguas \& Letras, v. 16, e Mulheres monstruosas: o ctônico e o selvagem em 'Carmilla', de Le Fanu. Publicado na revista Abusões, v.9. Recebeu o prêmio Dr. Virchez Scholarship em 2009 e tem interesse nos seguintes temas: sonho americano, crise utópica, cli-fi e feminismo. Lattes http://lattes.cnpq.br/1748010861441799 E-mail: mahhhp@gmail.com

Luiz Felipe Voss Espinelly é Doutor em História da Literatura pela Universidade Federal do Rio Grande - FURG, onde já atuou como professor da graduação de diversos cursos, nas disciplinas Teoria da Literatura II, Produção Textual e Estágio Supervisionado em Língua Portuguesa I. Autor do artigo $\mathrm{O}$ pós-humano e a poética pós-moderna em Androides sonham com ovelhas elétricas?, de 
Philip k. Dick, publicado na revista Desenredos, v. 23, com interesse nos seguintes temas: herói e anti-herói, utopia e distopia, pós-modernidade, literatura contemporânea, bildungsroman, ficção especulativa e ficção científica. Lattes http://lattes. cnpq.br/3316751576275246E-mail: luizyoung@yahoo. com.br

Resumo: Este trabalho busca analisar as relações entre monstruosidade e tecnologia na obra Androides sonham com ovelhas elétricas? (1968), de Philip K. Dick, a partir de uma aproximação do romance distópico em questão com o gótico e com estudos sobre o período no qual ele foi escrito. Sabendo que a literatura gótica foi muitas vezes descrita como uma expressão das ansiedades relacionadas a crises epistemológicas e sociais próprias de contextos históricos específicos, sua relação com a distopia é bem próxima, uma vez que o subgênero, que tem como base a crítica às estruturas e sistemas que regem a sociedade, também se utiliza de um discurso de desilusão frente ao mundo. Tendo isso em vista, este artigo propõe uma reflexão sobre a visão sombria do final da década de 1960, como surge no romance de Dick, e sua relação com a estética gótica.

Palavras-chave: Literatura norte-americana; Distopia; Gótico; Tecnologia; Monstruosidade.

Abstract: This paper presents an analysis of the relationship between monstrosity and technology in the novel Do androids dream of electric sheep? (1968), by Philip K. Dick, through an approximation of the dystopian novel in question with the Gothic and with studies that deal with the period in which the novel was written. Knowing that Gothic literature has often been described as an expression of the anxieties related to epistemological and social crises, typical of specific historical contexts, its relationship with dystopia is very close, since the subgenre, which is based on the critique 
of structures and systems that govern society, also uses a discourse of disillusionment with the world. With this in mind, this article proposes a reflection on the gloomy vision of the late 1960s, as it appears in Dick's novel, and its relationship to the Gothic aesthetics.

Keywords: North American Literature; Dystopia; Gothic; Technology; Monstrosity.

É possível localizar o gótico - no sentido literário - como um fenômeno histórico originado no final do século XVIII, no qual se pode apontar a persistência de alguns temas específicos. No entanto, para a crítica recente, mais do que um gênero aprisionado a um contexto sociocultural e artístico exclusivo, o gótico pode ser visto como um discurso utilizado por inúmeros outros gêneros e subgêneros para tratar de medos e ansiedades característicos de momentos históricos distintos (cf. PUNTER; BYRON, 2004, p.XVIII). A ficção especulativa, e mais especificamente o subgênero da distopia, nesse sentido, parece ter uma profunda afinidade com ele, uma vez que ambos criticam a sociedade moderna e demonstram preocupações, em certa medida, similares. Entretanto, há uma diferença significativa entre os dois tipos de narrativas, como observa Fred Botting, pois na ficção especulativa caracterizada também como científica "as ansiedades culturais do presente não são mais projetadas no passado, mas são realocadas para o futuro" (1996, p.102, tradução livre). Tendo isso em vista, a partir de uma aproximação com o gótico, este trabalho busca analisar as discussões sobre tecnologia e monstruosidade da forma como surgem na obra Androides sonham com ovelhas elétricas? (1968), de Philip K. Dick, propondo uma reflexão sobre a visão sombria do capitalismo tardio e sua relação com a estética gótica. 
Se o gótico tem seu surgimento normalmente conectado a um momento no qual a Grã-Bretanha estava mudando de uma estrutura social agrária para industrial, quando o capitalismo emergente mecanizou a produção e trouxe uma sensação de alienação e isolamento para o trabalhador, a distopia é geralmente relacionada à ficção científica, que tem sua própria origem na tradição literária gótica. Enquanto no século XIX os efeitos da industrialização fizeram com que o gótico saísse dos castelos e abadias e fosse para a cidade, na metade do século XX, as ansiedades causadas pelo boom tecnológico fazem com que a iminência do fim do mundo deixe de parecer algo tão fantástico (cf. PUNTER; BYRON, 2004, p. 24). Assim, narrativas que trabalham com a ideia de "último homem na terra" e com as ansiedades sobre o corpo e sobre os limites do que o homem pode criar vêm à tona. Aspectos já presentes em obras como The Last Man (1826) e Frankenstein (1818), de Mary Shelley, por exemplo.

Caracterizada por um estranhamento cognitivo por alguns críticos $^{1}$, pela importância da lógica da ciência ${ }^{2}$ e pela tentativa de imaginar futuros inimagináveis ${ }^{3}$ por outros, a ficção científica, vista por alguns teóricos como subgênero da ficção especulativa ${ }^{4}$, serve

1 Conforme Suvin, a "ficção científica é, então, um gênero literário cujas condições necessárias e suficientes são a presença e a interação do estranhamento e da cognição, e cujo principal dispositivo formal é uma estrutura imaginativa alternativa ao ambiente empírico do autor" (1979, p.7-8, tradução livre).

2 Conforme Parrinder, a "especulação realista sobre eventos possíveis no futuro, solidamente baseada no conhecimento adequado do mundo real, passado e presente, e num minucioso entendimento da natureza e importância do método científico" (1980, p.16, tradução livre).

3 Já para Jameson, "a ficção científica é geralmente entendida como a tentativa de imaginar futuros inimagináveis. Mas seu tema mais profundo pode de fato ser o nosso próprio presente histórico" (2005, p.345, tradução livre)

4 Atwood (2004) vai defender que algumas pessoas usam os dois termos como sinônimos, enquanto outras utilizam ficção especulativa como um termo guarda-chuva, sob o qual subgêneros podem se agrupar. Ficção especulativa pode ser utilizada como a árvore, na qual ficção científica, fantasia de ficção científica e fantasia são os galhos. 
de base para a distopia, que dialoga com tal tradição literária. Embora nem todos romances distópicos sejam exatamente ficção científica, Androides sonham com ovelhas elétricas? (1968) estabelece uma interlocução direta com essa tradição. Ao retomar o mito de Prometeu explorado no clássico gótico Frankenstein, o romance de Dick o contextualizado no futuro do capitalismo tardio e explora questões tecnológicas da década de 1960, abordando agora o poder das corporações - e não mais de um "criador" individual, como em Shelley. Na releitura do final da década de 1960, o monstro criado pelo humano se transforma em vários androides, ou andys, indistinguíveis dos seus criadores.

Como David Punter e Glennis Byron observam, "o gótico é frequentemente considerado um gênero que reemerge com força peculiar em tempos de crises culturais e que serve para negociar ansiedades da época ao trabalha-las de uma maneira deslocada" (2004, p.36, tradução livre). A distopia também assume a mesma característica e apresenta picos de produção em épocas de crise. Pressupondo uma sociedade imaginária, distinta da nossa, no futuro ou em um presente alternativo, ela critica os problemas da sociedade contemporânea através de seu exagero. M. Keith Booker, em Dystopian literature: a theory and research guide, confirma a relação de crítica à sociedade contemporânea ao afirmar que "a literatura distópica genericamente se constitui também como crítica às condições sociais ou sistemas políticos existentes" (1994, p.3, tradução livre), e Rudinei Kopp complementa que "as distopias são, portanto, formas para criticar, através da exacerbação, os regimes e modos vigentes" (2011, p.58). 
Androides sonham com ovelhas elétricas? (1968), de Philip K. Dick, surge em um desses momentos de crise. Publicado nos Estados Unidos durante a Guerra Fria, após duas experiências de guerras mundiais, da bomba atômica e de anos de testes nucleares - que seriam proibidos apenas em 1996, com o Tratado de Interdição Completa de Ensaios Nucleares -, o romance é lançado em um momento de medo político e de destruição ambiental causada pela intromissão cada vez maior do homem na natureza e pelas novas tecnologias que ameaçavam a própria vida terrestre. Retomando temáticas explícitas já em Mary Shelley, o romance de Dick explora os horrores que podem se seguir, caso o homem decida brincar de deus, suscitando dilemas políticos do capitalismo tardio enquanto revela também aspectos essenciais da estrutura narrativa e da visão de mundo da literatura gótica. Essa relação com o gótico talvez tenha ficado mais evidente, por conta de sua popularidade, na adaptação de 1982 de Ridley Scott, Blade Runner, que suscitou análises como a de Fred Botting em Gothic (1996):

O débito à Frankenstein é imenso. No Blade Runner de Ridley Scott, as insinuações ao gótico do século XIX estão sempre muito próximas da superfície do futurismo sombrio do filme de detetive. Ambientado em uma Los Angeles do futuro, lúgubre, em ruínas e alienante, o filme acompanha o destino de um grupo de 'replicantes' rebeldes, criações artificiais indissociáveis dos humanos, enquanto eles tentam, como o monstro de Frankenstein, fazer seu criador, o cientista que controla a corporação Tyrell, aceitar suas demandas por uma expectativa maior de vida. O caçador de androides descontente, Deckard, cuja tarefa é identificar e eliminar os replicantes, é o assunto paralelo do filme, que divide a simpatia 
entre perseguidor e perseguido. Presa entre caçador de androides e replicante, humano e androide, a narrativa gradualmente apaga as diferenças que distinguem um do outro, deixando dúvidas que assombram o final da primeira versão do filme. (BOTTING, 2005, p.106-107, tradução livre)

Androides sonham com ovelhas elétricas? se passa em um futuro próximo, pós-apocalíptico, em que a Terra e seus habitantes foram dizimados pela Guerra Mundial Terminus e os sobreviventes instigados a emigrarem para colônias em Marte. Entre os poucos que ficaram, se encontram um caçador de androides e sua esposa, um grupo de androides orgânicos criados geneticamente indistinguíveis dos humanos e alguns seres considerados "Especiais", que foram impedidos de emigrar por não serem considerados saudáveis para tal fim. Segundo o narrador:

Vagabundear pela Terra significava,
potencialmente, ver-se de súbito classificado
como inaceitável biologicamente, uma ameaça
à imaculada hereditariedade da raça. Uma vez
classificado como Especial, um cidadão, mesmo
que aceitasse ser esterilizado, era excluído dos
registros da história. Efetivamente, ele cessava de
fazer parte da humanidade. (DICK, 2019, p.42)

Embora com finais um pouco diferentes, sendo o do livro bem menos otimista que o do cinema, tanto a obra literária quanto a adaptação cinematográfica trabalham com a crise identitária de Deckard, dos que escolheram ou foram impedidos de emigrar e dos próprios androides, como Rachael, que nem mesmo se reconhece como máquina, por conta das memórias nela implantadas. São todos assombrados pelo medo de serem, 
no fundo, seres não-originais. A busca por fixidez e segurança em um mundo que parece sem sentido faz com que os personagens se segurem ao passado e ao espaço da Terra, que é vista como "familiar, algo a que se apegar", uma vez que eles pareciam não emigrar porque imaginavam "que a poeira pudesse se dissipar um dia" (DICK, 2019, p.28), contribuindo para que sintamos simpatia pelos personagens, quer sejam humanos ou androides. Afinal, nada mais humano do que se apegar ao passado na esperança que o presente volte a ser como antes.

A história de um mundo devastado e quase vazio, habitado apenas pelos desajustados da sociedade, que são relembrados de sua marginalidade pelo slogan que passa na televisão "Emigre ou degenere! A escolha é sua!" (DICK, 2019, p.34) - embora muitos não tenham escolha de emigrar ${ }^{5}$-, lembra bastante a ideia de contaminação intrínseca às narrativas de monstros que assombravam a sociedade Vitoriana. No entanto, a contaminação aqui não vem de uma criatura identificada por sua monstruosidade, geralmente ligada ao sobrenatural, e da possibilidade de ela desestabilizar a sociedade burguesa, mas dos próprios humanos. Ao contrário de histórias como Drácula (1897), de Bram Stoker, e Carmilla (1872), de Le Fanu, por exemplo, nas quais o monstro é classificado racional e cientificamente como tal, a fim de não deixar dúvidas quanto a sua falta de humanidade, em distopias como a de Dick o monstro embaça a lente racional. Ele não apenas é exposto como tão humano quanto seus criadores, ele é mesmo

5 Importante lembrar que nem todos tinham escolha, como Isidore nota: "Mas os anúncios, dirigidos aos Normais remanescentes, o terrificavam. Informavam-no, de um infindável número de maneiras, que ele, um Especial, não era desejado. Não tinha utilidade. Não poderia emigrar, mesmo que quisesse fazê-lo" (DICK, 2019, p.46). 
indissociável deles e, talvez, até mesmo mais humano, como avisa a corporação Tyrell do filme de Ridley Scott ${ }^{6}$. No romance de Dick, nem o teste mais avançado, chamado de Voight-Kampff, é capaz de diferenciar os androides Nexus-6 dos seres orgânicos, uma vez que ele utiliza a empatia para medir a humanidade e ambos parecem ter atingido níveis semelhantes em algum momento.

Assim como nos dois exemplos de narrativas de vampiros citados anteriormente, Punter e Byron observam que os romances góticos trazem anseios em relação às possibilidades do primitivo "infectar o mundo civilizado" (2004, p.40, tradução livre). No romance de Dick, por outro lado, além de não existir mais o primitivo, o próprio "mundo civilizado" é exposto como o responsável por haver contaminado a sociedade. As florestas, animais ou qualquer outro aspecto relacionado a uma natureza primeira foram eliminados quase em sua totalidade pela Guerra Mundial Terminus, pela má utilização da tecnologia existente e pela ganância das corporações, que infectou a atmosfera do planeta a ponto de ser necessário emigrar para Marte. O pouco que restou do mundo natural se tornou propriedade dos que controlam a Terra, como Deckard descobre ao visitar a Corporação Rosen:

Todas as nossas aquisições provêm de entidades privadas, e os preços que pagamos nunca são divulgados. Além do mais, temos nossos próprios naturalistas; agora estão trabalhando no Canadá. Ainda há ali uma boa extensão de florestas remanescentes, em comparação com as nossas, por assim dizer. O suficiente para animais pequenos e, de vez em quando, um pássaro. (DICK, 2019, p.66)

6 No filme de 1982 a corporação não se chama Rosen, como no livro, mas sim Tyrell, e em uma cena clássica, o presidente da corporação diz ao personagem de Harrison Ford (Deckard) que o lema deles é "more human than human". 
Em Androides sonham com ovelhas elétricas?, nada está imune à contaminação humana. Nada além dos poucos quilômetros no Canadá que são controlados pelos mesmos que contaminaram e destruíram o resto do mundo. Em uma sociedade na qual humanos precisam de sintetizadores de humor para terem emoções adequadas e de caixas de empatia para sentirem algo, os androides apreciam $\operatorname{arte}^{7}$ e se questionam sobre sua humanidade. Não há mais distinção entre o natural e o artificial e, assim, a própria originalidade do humano é contestada. Como Tomas Tadeu da Silva destaca: "A ideia do ciborgue, a realidade do ciborgue, tal como a da possibilidade da clonagem, é aterrorizante, não porque coloca em dúvida a origem divina do humano, mas porque coloca em xeque a originalidade do humano" (2000, p.14).

Na narrativa de Dick, a contaminação é inevitável e não existe mais distinção entre humano e não humano. A tentativa de "limpar" a sociedade do que é impuro - ou seja, dos seres máquinas indistinguíveis dos seus criadores - é frustrada. Embora o emprego de Deckard seja aposentar os androides, seguindo o desejo moderno de separar a impureza da pureza, uma vez que, como Mary Douglas observava, "a sujeira ofende a ordem e eliminá-la não é um movimento negativo, mas um esforço positivo de organizar o ambiente" (2014, p.12), o caçador falha. Não é mais possível distinguir as duas coisas, são todos mortosvivos no final das contas.

Essa contaminação, uma das causas de horror no romance, mostra a clara concepção de que os avanços tecnológicos da época

7 Luba Luft, uma das androides fugitivas, é uma renomada cantora de ópera (cf. DICK, 2019, p.145) que se interessa pela obra "Puberdade", de Munch. 
de publicação da obra iriam alterar a experiência humana em níveis fundamentais. E deslocando essa ansiedade para o futuro, Dick narra a história de personagens que ultrapassaram uma barreira e se tornaram seres mistos de compostos artificiais e carne. O romance joga com a ideia do pós-humano como etapa final do processo de evolução do homem, que se torna um ser híbrido que une o orgânico ao tecnológico para transcender as limitações humanas. O mais assustador, no entanto, é que o controle de emoções pelo sintetizador Penfield, por exemplo, é bastante similar aos remédios que já existiam, como o Diazepam, que começou a ser comercializado no início dos anos de 1960. O futuro, nesse sentido, é bem parecido com o presente da produção da obra. Para Donna Haraway, em $O$ manifesto ciborgue (1985), a originalidade do humano é um tema recorrente nas narrativas porque já somos ciborgues, pelo uso que continuamente fazemos das tecnologias, bem como por outros fatores. A pesquisadora observa que "no final do século $X X$, neste nosso tempo, um tempo mítico, somos todos quimeras, híbridos - teóricos e fabricados - de máquina e organismo; somos, em suma, ciborgues" (2000, p.37).

O romance de Dick revela essa realidade. Contudo, não é apenas o controle das emoções que tornou todos ciborgues. A destruição ambiental, a ganância coorporativa, o poder econômico concentrado na mão de $1 \%$ da população, as políticas públicas ineficientes e a apatia frente aos grupos marginalizados que são sempre os primeiros a sofrerem as consequências das crises marcam a nossa falta de humanidade. A crise de identidade de Deckard, refletida na crise de identidade dos próprios androides, coloca esse aspecto em evidência. A tentativa de resgatar o primitivo, com a insistência do 
caçador em possuir um animal de verdade e não apenas elétrico, como sua ovelha, apenas intensifica a artificialidade dos próprios humanos, que veem algo com vida como um objeto para atingir prestígio social:

A coisa que mais sonhava no mundo era em ter um cavalo, de fato qualquer animal. Ser dono de uma fraude era algo que ia gradualmente desmoralizando qualquer um. No entanto, do ponto de vista da sociedade, era necessário, dada a ausência de um artigo autêntico. (DICK, 2019, p.35)

A natureza que os personagens buscam, e que já está até mesmo na reflexão encabeçada pelo título do romance, não é no sentido de possuir animais para tentar preservar as espécies ou como desejo de retorno ao primitivo e à wilderness estadunidense já devastada. Os animais maiores são mantidos amarrados nos terraços de prédios, independentemente de suas necessidades, e forçados a viver sob péssimas condições ambientais - não se esquecendo da poeira tóxica - a fim de suprir vontades individuais que nem são essenciais, na realidade, são apenas afirmações de status e uma forma de diferenciar humano de androide, uma vez que androides não sentem empatia e seria pouco provável que eles teriam condições de cuidarem de um animal. Ou pelo menos é o que supõe Deckard no início do romance.

Os espaços preservados no Canadá, com alguns animais pequenos e árvores, disponíveis apenas para os mais ricos, colocam em evidência o futuro amedrontador que aguarda a humanidade. Apenas com pequenos animais capazes de sobreviver nesses ambientes controlados "e, de vez em quando, um pássaro" (DICK, 2019, p.66), o medo que esse futuro apresenta é pautado no próprio 
presente da produção da obra. Com pesquisas científicas como a de Rachel Carson, em Silent Spring (1962), que já avisava que "apenas no período representado pelo século presente uma das espécies o ser humano - adquiriu poder significativo para alterar a natureza do mundo" (2002, p.6, tradução livre), imaginar a extinção desses animais não requeria muita imaginação na década de 1960 . No estudo, a bióloga acusava a utilização do DDT como responsável pela morte de pássaros e apontava o desastre ambiental para o qual o mundo se encaminhava. Crítica bem compreendida por Philip K. Dick poucos anos depois, quando ele descreve a destruição da Terra pela Guerra Mundial Terminus dizendo que "a primeira coisa que aconteceu foi a estranha morte das corujas. [...] Depois das corujas, claro, seguiram-se outros pássaros" (DICK, 2019, p.41-42). Em um ambiente tão inóspito, não é de surpreender a apatia e a falta de sentimentos dos personagens que lá habitam, afinal, como já avisava Carson, "na natureza, nada existe sozinho" (2002, p.51, tradução livre) e, se o planeta morre, os humanos inevitavelmente terão o mesmo fim.

Em relação a essa projeção que a ficção científica tende a fazer dos problemas e angústias da sua época no futuro, bastante similar à da literatura gótica, que por sua vez as projeta no passado, Dick brinca com seu leitor ao fazer os androides entusiastas por ficção "pré-colonial". O termo, utilizado para se referir à ficção científica produzida na Terra antes do desastre ambiental, surge em um diálogo entre Pris, uma das androides Nexus-6 fugitivas, e Isidore, um Especial conhecido como "cabeça de galinha". No diálogo, Pris conta para Isidore como as ficções pré-coloniais, que são encontradas nas bibliotecas vazias da Terra e enviadas para 
Marte por uma fortuna, são populares no planeta vermelho. Ela complementa: "Nada é tão excitante quanto isso. Ler sobre cidades e enormes corporações industriais, e colonizações realmente bemsucedidas. O que Marte deveria ser" (DICK, 2019, p.162). A ficção científica, produzida no passado dos personagens e projetando um futuro melhor e diferente do vivenciado por eles, se torna um conforto, pois retrata uma forma de colonização que foi mais bemsucedida que a do seu tempo. Algo que nos mostra também como o mundo pode ser ainda muito pior do que o retratado na ficção, caso as políticas globais não mudem.

No mundo de Deckard, dos Nexus-6 e dos Especiais, o vazio parece assustar mais o leitor do que os próprios personagens, anestesiados pelos sintetizadores, caixas de empatia, mercerismo (a religião da maioria deles) e degenerações causadas pela poeira tóxica. O espaço sombrio que eles habitam, embora conhecido pelos leitores, é, no futuro alternativo da narrativa, um lugar distante e morto. Enquanto romances góticos como Frankenstein colocavam seus personagens em ambientes "distantes, selvagens e inexplorados" (JAKOVLJEVIC, 2017, p.172, tradução livre), na distopia de Dick vemos o mundo que conhecemos, mas completamente transformado em um universo alternativo que se assemelha bastante aos espaços das narrativas de horror:

Silêncio. Cintilou a partir do madeiramento e das paredes; golpeou-o com uma potência terrível e total, como se fosse gerado por uma imensa usina. Crescia, saindo do carpete esfarrapado que cobria todo o chão. Soltava-se dos quebrados e semidestruídos utensílios da cozinha, as máquinas mortas que nunca tinham funcionado desde que 
Isidore havia se mudado para ali. Goteja da inútil luminária na sala, entretecido à sua própria queda vazia e muda desde o teto salpicado de moscas. (DICK, 2019, p.45)

Vivia sozinho em seu deteriorado edifício de milhares de apartamentos inabitados, que, como todas as suas partes constituintes, caía, dia a dia, dentro de uma enorme ruína entrópica [...] Alcançou a maçaneta da porta que abria o caminho para um corredor escuro e então se encolheu ao vislumbrar a vacuidade do resto do edifício. [...] Não estava pronto para passear pelas escadas rangentes até o terraço vazio onde não tinha nenhum animal". (DICK, 2019, p.46-47)

As cadeiras, o carpete, as mesas... tudo havia apodrecido; cederam à ruína simultaneamente, vítimas da despótica força do tempo. E do abandono. Ninguém havia vivido neste apartamento por anos; o estrago agora era quase completo. Não conseguia imaginar como ela pensava em morar numa vizinhança dessas. (DICK, 2019, p.85-86)

O espaço, além de assustador por ser abandonado, é assombrado pelo passado dos personagens. É um lembrete diário da guerra, da deterioração humana, do vazio e dos monstros que causaram tudo isso. É um lembrete do consumo exacerbado que é marca do capitalismo tardio e também é um fator ambiental de risco que contribui para a atmosfera distópica. O termo kipple, criado por Philip K. Dick e traduzido para o português como "bagulho", representa bem o horror dos personagens. Utilizado em Androides sonham com ovelhas elétricas? no sentido de proliferação da sujeira e do caos, o termo se refere a toda sujeira que se reproduz e absorve seu entorno, se expandindo, como 
explica o personagem Isidore: "Bagulho é todo tipo de coisa inútil, como correspondências sem importância, caixa de fósforos vazia, embalagem de chiclete ou homeojornal de ontem. Quando ninguém está por perto, o bagulho se reproduz" (DICK, 2019, p.86). Isidore complementa sua explanação esclarecendo sobre as propriedades entrópicas do kipple: "É um princípio universal que opera por todo o cosmo; o universo inteiro está se movendo na direção de um estado final de total e absoluta bagulhificação" (DICK, 2019, p.87). Kipple é como uma assombração. São os objetos inanimados descartados pelos humanos engolindo o planeta para se vingar dos que os produziram e consumiram.

O questionamento de Deckard sobre a falta de humanidade dos próprios humanos é trazido à tona para criticar o mundo que possibilita a criação do "bagulho", com suas armas químicas, o consumo e os problemas do capitalismo tardio que retiram cada vez mais as condições básicas de vida das pessoas enquanto elas parecem anestesiadas pelas distrações que o mesmo sistema produz. Na tese Prophet of the postmodern: The problem of authenticity in the works of Philip K. Dick (2008), o pesquisador canadense Bradley Congdon relaciona o contexto de artificialidade da sociedade com a própria desumanização:

Não é coincidência que um mundo desordenado com alimentos falsos, imitação de recursos e emoções eletrônicas é povoado com humanidade simulada, tanto sob a forma de androides quanto seres humanos "autênticos", como Iran, que parecem ter perdido as emoções que nos fazem verdadeiramente humanos. (CONGDON, 2008, p.43, tradução livre) 
A vida artificial do mundo distópico de Dick, uma clara referência à sociedade de consumo que necessita de objetos para preencher o vazio do capitalismo tardio, transforma até o desejo pela natureza e por um ser vivo em commodities, tamanha a falta de humanidade dos personagens. Da mesma forma, a emigração também assume o mesmo papel que o consumo. Os que não são aptos a saírem da Terra, e que porventura venham a serem classificados como inaceitáveis biologicamente, não são considerados cidadãos e são apagados dos registros da história.

Se as paisagens góticas são "ermas, alienantes e cheias de ameaças" (1996, p.2, tradução livre), como Fred Botting observa, em Androides sonham com ovelhas elétricas?, além delas, os próprios humanos também podem ser descritos como portando as mesmas características. A monstruosidade aqui se dá na falta de empatia, na "ausência de afeto adequado" (DICK, 2019, p.31), bem representada na personagem de Iran, sempre ligada ao seu sintetizador Penfield, e que percebe, mesmo no "estado de espírito 382" (DICK, 2019, p.31), o quanto a falta de vida ao seu redor era doentia, mas resolve manejar o sintetizador para encontrar um ajuste para a desilusão. A diferença entre um androide e um humano com sentimentos programados por uma máquina parece ser apenas de que o androide talvez seja mais humano, pois pelo menos eles parecem sentir medo, raiva e outros sentimentos sem a necessidade de utilizar um sintetizador. Os monstros na obra de Dick não são mais as criaturas, mas sim os criadores que contribuíram para a destruição do planeta. Tenha sido efetivamente, como as corporações, ou silenciosamente, como cidadãos apáticos que não viam motivos para questionarem as políticas vigentes. 
Como Fred Botting vai apontar, há uma mudança na figura do monstro. Eles são, na literatura mais recente:

Lugares de identificação, simpatia e reconhecimento. Figuras excluídas, antigamente representadas como malvadas, perturbadas ou monstros anormais, são representadas como mais humanas, enquanto o sistema que as exclui assume formas aterrorizantes, perseguidoras e inumanas. (2002, p.286, tradução livre)

O romance, ao mostrar os humanos como os realmente monstruosos, aponta para o fato de que a figura do estrangeiro invadindo o planeta - e é importante lembrar que os androides vêm de colônias de Marte - não é o problema. O problema é o sistema que os produziu e que agora os persegue a fim de "aposentá-los" (DICK, 2019, p.36) - ou, retirando o eufemismo do romance, de matá-los. É o sistema capitalista global que, ao perder o controle dos corpos humanos, uma vez que a os habitantes da Terra foram expostos à poeira tóxica que ameaça a reprodução ${ }^{8}$ e muitos se tornaram inférteis, quer produzir novos corpos a fim de continuar suas explorações.

A expansão para Marte - nada mais do que uma referência às privatizações de terras, às práticas neoliberais, que colocam países menos desenvolvidos à mercê das grandes potências, e às políticas de globalização - pode ser compreendida como uma crítica ao capital e suas relações com o trabalho e a reprodução através de um exagero palpável na diegese. Em Dick, é denunciada uma escalada

8 Conforme fica explícito na obra, a poeira causou infertilidade e quem está na Terra é obrigado a usar protetores genitais de chumbo para proteção e fazer testes regulares para confirmar se ainda poderiam se reproduzir "dentro das cotas toleradas pela lei" (DICK, 2019, p.34). 
no poder sobre os corpos e os direitos reprodutivos, tão discutidos na época de publicação do romance através dos movimentos hippie, de direitos civis, com a segunda onda feminista e com o surgimento das Forças Armadas Revolucionárias nos países de 30 mundo. O romance lida diretamente com o assunto ao descrever a posição dos androides na sociedade: após serem explorados em Marte como corpos disponíveis para exploração sexual e diversos outros tipos de trabalho, são "aposentados" pelo estado quando deixam de ser úteis ou quando se tornam perigosos a ponto de se perceberem como os humanos e quererem fugir do controle do status quo. A visão crítica sobre a condição dos andys é exposta por Roy Baty, androide líder dos rebeldes e responsável pelo despertar político de sua classe. Não coincidentemente, o mais assustador para Deckard:

Parado ali, em pé, ele percebeu, de repente, que havia adquirido um medo patente, incontestável por aquele androide líder. Tudo dependia de Baty - tudo tinha dependido dele desde o começo. Até então ele havia encontrado e aposentado manifestações de Baty de maneira progressiva, uma mais ameaçadora que a anterior. Agora chega a vez de Baty, propriamente dito. Ele pensava em como sentia o medo crescer; o medo tomou-o completamente, agora que ele havia deixado esse sentimento se aproximar de sua mente consciente. (DICK, 2019, p.198)

Baty se revolta contra o sistema e, em vez de perceber o androide como um monstro, Deckard o teme pelo seu poder. Afinal, como uma máquina conseguiu ser mais transgressora que os próprios humanos? É um fato que a representação e 
interpretação da monstruosidade costuma mudar de acordo com o tempo. Androides sonham com ovelhas elétricas?, imerso em um momento histórico marcado pela ameaça constante da bomba atômica e pelas narrativas nacionais que apontavam um inimigo claro e definido - no caso dos Estados Unidos da década de 1960, os russos -, foge das oposições binárias e das divisões entre "nós" e "eles" em uma distopia permeada pela tecnologia e pelo diálogo direto com o clássico gótico de Mary Shelley. Com um protagonista cuja profissão remete a uma figura heroica, algo de extrema importância para a construção identitária dos Estados Unidos, o caçador responsável por salvar o país dos monstros estrangeiros que ameaçam a ordem se transforma em antiherói. Deckard desconstrói o mito nacional do frontiersman, do cowboy e de qualquer figura masculina exaltada pela sua força e por defender a pátria ao se apresentar como confuso e em crise. Inclusive, é o próprio Deckard quem expõe abertamente quem são os verdadeiros vilões que precisam ser parados, no caso, o sistema capitalista e neoliberal estadunidense que parece empenhado em destruir o planeta enquanto foca no lucro. São eles os verdadeiros monstros com os quais não devemos simpatizar.

Ao projetar as ansiedades da conturbada década de 1960 em um futuro não muito distante, o romance de Philip K. Dick lida com o medo da falta de autenticidade, da contaminação, da possibilidade de não haver mais vida na Terra e da possível intensificação da apatia tão comum ao capitalismo tardio - e já mais do que discutida por teóricos como Fredric Jameson, Jean Baudrillard, entre outros. Os personagens do romance, muito parecidos com zumbis e com os próprios vampiros Vitorianos, são mortos-vivos em um mundo 
gradativamente sendo engolido pelos próprios objetos e seres artificiais que os humanos criaram. O romance apresenta um futuro assombrado pelos medos da década de 1960, e as assombrações tomam forma para manifestar os conflitos e as mudanças que não podem mais ser ignoradas. Assim, os monstros de Dick cumprem o seu papel, eles apontam para os problemas e indicam que os androides não são mais humanos que os humanos, como dizia o lema da corporação Tyrell no filme de Ridley Scott, mas que os humanos é que são mais monstruosos do que os androides poderiam ser.

\section{REFERÊNCIAS}

ATWOOD, Margaret (2004). "The handmaid's tale and Oryx and Crake in context", Modern Language Association, 119(3), 513-517.

BLADE RUNNER - O CAÇADOR DE ANDROIDES (1982). Ridley Scott (Dir.). EUA: Warner Bros. 1 filme (117 min), dolby stereo, color. Título original: Blade Runner. BOOKER, M. Keith (1994). Dystopian literature: A theory and research guide. Wesport, CT: Greenwood Press.

BOTTING, Fred (2002). "Aftergothic: Consumption, Machines, and Black Holes." In: HOGLE, Jerrold E. (Ed.), The Cambridge Companion to Gothic Fiction. Cambridge: Cambridge University Press. (1996). Gothic. New York: Routledge.

CARSON, Rachel (2002). Silent Spring. USA: Houghton Mifflin.

DICK, Philip K (2019). Androides sonham com ovelhas elétricas?. São Paulo: Aleph. DOUGLAS, Mary (2014). Pureza e perigo. São Paulo: Perspectiva.

HARAWAY, Donna J (2000). Manifesto ciborgue: Ciência, tecnologia e feminismosocialista no final do século XX. In: SILVA, Tomaz Tadeu da (Org.) Antropologia do ciborgue: as vertigens do pós-humanismo. Belo Horizonte: Autêntica.

KOPP, Rudinei (2011). Comunicação e mídia na literatura distópica de meados do século 20: Zamiatin, Huxley, Orwell, Vonnegut e Bradbury. Tese (Doutorado em Comunicação Social) Pontifícia Universidade Católica do Rio Grande do Sul, 
Porto Alegre. In http://tede2.pucrs.br/tede2/bitstream/tede/4473/1/433625. pdf. Acesso em 07.Jun.2016.

JAMESON, Fredric (2005). Archaeologies of the future: The desire called utopia and other science fiction. New York: Verso.

JAKOVLJEVIC, Mladen (2017). "Do Androids Dream of a Modern Prometheus?". In: BABIC; Z. BIJELIC, T. Rethinking Tradition in English Language and Literary Studies. UK: Cambridge Scholars Publishing.

PARRINDER, Patrick (2003). Science fiction: Its criticism and teaching new accents. New York: Routledge.

PUNTER, David; BYRON, Glennis (2004). The Gothic. United Kingdom: Blackwell Publishing Ltd.

SILVA, Tomaz Tadeu da (Org.) (2000). Antropologia do ciborgue: as vertigens do pós-humanismo. Belo Horizonte: Autêntica.

SUVIN, Darko (1979). Metamorphoses of science fiction: On the poetics and history of a literary genre. New Haven: Yale University Press. 